\title{
Analysis of Mountains May Depart's Subtitle Translation from the Perspective of Skopos Theory
}

\author{
Qinhua Ji \\ School of Humanities, Tiangong University, Tianjin, China \\ Email: qinhuaji2020@163.com
}

How to cite this paper: Ji, Q.H. (2021) Analysis of Mountains May Depart's Subtitle Translation from the Perspective of Skopos Theory. Open Access Library Journal, 8: e7404

https://doi.org/10.4236/oalib.1107404

Received: April 9, 2021

Accepted: May 8, 2021

Published: May 11, 2021

Copyright () 2021 by author(s) and Open Access Library Inc.

This work is licensed under the Creative Commons Attribution International License (CC BY 4.0).

http://creativecommons.org/licenses/by/4.0/

\section{(c) (i) Open Access}

\begin{abstract}
Translation plays a prominent role in cross-cultural exchanges. And movies, as one of major tools in spread of culture, need to be accurately and clearly translated so as to a better echo. This paper aims to analyze the subtitle translation of Mountains May Depart from the perspective of Skopos theory. And the subtitle corpus of it is to be selected and analyzed. The result indicates that subtitle translation adheres to Skopos rule and coherence rule first, and follows or disobeys fidelity rule to some extent. The use of domestication or reduction can basically make subtitle translation understandable and acceptable. Moreover, cultural elements, especially dialects are supposed to adhere to fidelity rule on the basis of coherence rule. Through this analysis subtitle translation can be better optimized. However this paper fails to further discuss to what extent fidelity rule should be obeyed or violated.
\end{abstract}

\section{Subject Areas}

Translation

\section{Keywords}

Skopos Theory, Mountains May Depart, Subtitle Translation

\section{Introduction}

Globalization has greatly promoted cultural exchanges, and movies, as one of the main tools, are playing an increasingly bigger role in communication or even the spread of culture. Thus subtitle translation is of great significance. It combines with pictures and dubbing and aims to express best effects while Skopos theory indicates that a translation should always be conducted to fulfill the purpose of 
the target text in the target text's situation. Thus it is appropriate to analyze subtitle translation based on Skopos theory. And Mountains May Depart, full of dialects and directed by famous director Jia Zhangke, tells the vicissitudes of individuals and society of three periods from 1999 to 2025. Thus this paper aims to analyze the subtitle translation of Mountains May Depart from the aspect of Skopos theory. How Skopos theory is reflected in subtitle translation? And what points or notes can be concluded for the subtitle translation? Data from syntax level and discourse level are chosen and analyzed respectively. Furthermore, this paper is divided into five parts. The first part is a brief introduction of research background. The second part displays the literature review both at home and abroad. Then theoretical basis includes definition, three principles and the feasibility of Skopos theory to study subtitle translation. The next part shows Mountains May Depart and collected examples with local color are classified and analyzed. Then conclusion is drawn.

\section{Literature Review}

The definition of subtitle is not yet authorized. One of the definitions in the Oxford English Dictionary is that subtitles are words that translate what is said in a film or movie into a different language and appear on the screen at the bottom.

\subsection{Subtitle Translation at Abroad}

Studies of subtitle translation started very early abroad, especially in Europe.

About the mid- $19^{\text {th }}$ century, audiovisual translation firstly appeared on academic papers. Two papers, Traduction et Cinema published in 1956 and Cinema et Traduction published on Bebal in 1960 were seen as the earliest papers of subtitle translation in the west. But later it developed slowly.

Until 1974, "On Subtitles in Television Programs" written by Cay Dollerup marked the real beginning of subtitle translation. In this paper, the subtitle errors appearing on TV programs from English to Danish were intensively clarified and subtitle translation could be considered as a way of foreign language teaching. It was indeed helpful to latter translation studies [1].

In 1982, Titford published Subtitling: Constrained translation which discussed the constraints imposed on translators and limitations of film subtitles on time and space [2]. And then some scholars such as Kelly, Mayoral Asesio and Gallardo put thoughts into practice.

In 1987, the first conference of subtitle translation which was mainly about dubbing and subtitles was held by European Broadcasting Union. After that, lots of studies were done to promote the development of subtitle translation.

Then the florescence came with two published books: Overcoming Language Barriers in $T V$ written by famous professor Luyken and four linguists in 1991 and Ivarsson's Subtitling for the Media published in 1992. It was believed to be the first book ever to deal specifically with titles. Since 1995, film and television translation was eventually established as an independent role in research field as European Film and Television Translation Association appeared. 
Since the beginning of $21^{\text {st }}$ century, subtitle translation has begun to enter into professional stage due to advancement of technology and cultural exchanges. And Vermeer believed Skopos theory can be used to guide the subtitle translation.

\subsection{Subtitle Translation at Home}

Subtitle translation started very late in China. And a comprehensive and systematic theory is not yet to be established. In 1949, a Russian film- $A$ Common Solider was translated into Chinese for the first time which symbolized the beginning of study on the subtitle translation in China.

In 1997, Ma Zhengqi, a founder of Chinese film translation, mainly studies film translation and cross-cultural communication. "In a famous book named An Introduction of Film Translation, he analyzed fundamental principles of film translation from five perspectives: be colloquial language; be in accordance with character's personality; satisfy the emotional needs of the film; achieve lip-synchronization; be popular language [3]."

In 1998, Zhang Chunbai, an initiator of subtitle translation in China, emphasized the instantaneity and popularity of translation and advocated that the main approach of subtitle translation is free translation, especially cultural items [4].

In 2000, Qian Shaochang is a leading figure in subtitle translation in China. He has translated many films such as Growing Pains, Grand Hotel and so on. Then he published More and More Important Realm and distinguished subtitle translation from literary translation. In this paper, five features of subtitle translation: audio, comprehensiveness, transience, popularity and non-comment were taken into consideration [5].

In 2001, Li Yunxing, a prestigious professor, published "Strategies for Translation Subtitles" in Chinese Translators Journal, pointing out the features of subtitle translation [6]. And in 2002, Zhao Chunmei, also published her work Translation into Chinese of Film Scripts and Scripts of TV Drama Series-Four Main Conflicting Demands which is about four pairs of contradictions [7].

From 2004 to 2010, subtitle translation begun to receive attention in China. According to China National Knowledge Infrastructure (CNKI), about 498 papers had been published during this period. And from 2011 to the present, about 4076 research papers have been published which indicates a ten-fold increase. Interdisciplinary research was conducted during this period such as interdisciplinary research combining psychology, film and television, sociology and aesthetics, for example, Wu published Subtitle Translation from the Reception Aesthetics Theory in 2013 [8] and TanYang published On Subtitle Translation Strategies of the TV Program If You Are the One from the Perspective of Skopos Theory in 2020 [9]. And most of researches focus on translation strategies and methods.

\section{Theoretical Framework}

\subsection{Definition}

Skopos, a Greek term, usually refers to the aim or purpose of translation. The 
formation of Skopos theory has undergone a long and complicated process. At first, Katharina Reiss, the founder of German Functionalist School of translation, introduced and emphasized functional feature to translation studies. In 1978, Framework for a General Translation Theory was published as the basis of Skopos theory. And then in 1984, Skopos theory was formally put forward by Hans. J. Vermeer. The book indicates that translation is not only a language process but an activity that transfers both language and non-verbal communication symbols into another language [10]. Thus translation is a human act and every act has an aim orpurpose. Skopos theory believed that translation no longer revolves around original text. It is a purposeful and resultant act on the basis of source text which must be accomplished by negotiation.

After the emergence of three principles, the standard of translation is not "equivalence" any more but adequacy of target of translation. At the same time, Vermeer also proposed "translation appointment" which means whether, when and how to accomplish translations should be decided by translators [10]. That is to say, translators can use corresponding translation strategies and decide which parts can be retained or modified in accordance with different translation purposes. In light of Vermeer, the supreme rule in translation ought to be the Skopos principle which also means that Skopos of translation determines the translation methods and strategies.

\subsection{Three Rules}

\subsubsection{Skoposrule}

The first and foremost principle of all translation activities is "Skopos rule", also called "purpose principle". And several definitions are presented by different scholars. Here definition of Nord is to be introduced. "Translate/interpret/speak/write in a way that enables your text/translation to function in the situation in which it is used and with the people who want to use it and precisely in the way they want it to function [11]." It can be understood as translation purposes determine translation methods and strategies. In Nord's words, ends justify means.

The purpose of translation activity can be divided into three kinds: basic purpose of translator, communicative purposes of target text and purpose achieved by using specific translation strategies or means. However, the purpose usually refers to the communicative purpose which means communicative function of the translation in the target social and cultural context. So translator can specify its purpose in given context and then decide which translation methods are supposed to be adopted. And among several kinds of purposes, the most important precedes less important ones. For example, if the main purpose is to entertain foreign audience, the translation is supposed to be applied to culture of target text.

\subsubsection{Coherence Rule}

Coherence rule indicates that translation ought to comply with intra-textual co- 
herence which means the translation is supposed to be understandable and acceptable among target audience and meaningful in both target culture and communicative situations in which translation is used. Therefore, "the translator should take full account of the cultural background and social environment of the intended recipient in order to create a translation that is meaningful to the recipient [12]." Thus both source culture and target culture should be taken into consideration. To some extent, coherence rule requires a balance between two cultures and tries to make the translation understandable and acceptable among target audience.

\subsubsection{Fidelity Rule}

Fidelity rule refers to the inter-textual coherence between source text and target text. It is similar to other translation theories which claim to be faithful to original text. However, the purpose of translation and translator's understanding of text decide how faithful the translation is to original text.

And loyalty principle was put forward by Nord who found the existence of two defects of Skopos theory. The first one is that due to cultural diversity, people in different cultural backgrounds express different opinions towards good translation. The others are the communicative purpose of translation required by Skopos rule is in conflict with original writer's intention. Under the circumstances, Skopos rule is obeyed and fidelity rule is violated. So Nord proposed loyalty rule to cope with the relation between cultural differences and participants of translation. Loyalty rule has two parts. For one thing, translators are morally responsible for recipients and should explain everything they do and the reasons. For another, translators ought to be loyal to the original writer [11]. They are supposed to respect the original writer and coordinate target language with the writer's intention. Thus loyalty rule focuses on the relation between translation and original writer, clients, recipients and so on. Nord added functionality plus loyalty rule to Skopos theory and improved Skopos theory.

Both Skopos theory and subtitle translation emphasize aims or purposes. Thus it is feasible to study subtitle translation from the perspective of Skopos theory.

\section{Analysis}

\subsection{Purpose of Subtitle Translation in Mountains MayDepart}

Mountains May Depart, a right work of Jia Zhangke, records the vicissitudes of 26 years and the people of a small county, Fenyang. And the foremost aim of Mountains May Depart is to present and record the lives or vicissitudes of people at the bottom and to reflect the changes of society through the change of individuals. The changes of society shows that the prosperity of life cannot solve the dilemma brought about by blind resource exploitation, but bring about a large number of problems such as leftover men, broken family, no country for old men, corruption and so on. And the fast changes of society result in the return of soul [13]. Thus Mountains May Depart is to reflect the theme: the 
changes of individuals, their soul and society. And the first and foremost subtitle must be understandable and acceptable for foreign audience. Then it is to present the folk life and local color of china and to further spread Chinese culture finally.

\subsection{Analysis of Examples}

In the following part, examples with dialect color are selected and analyzed according to Skopos theory. And as mentioned above, Skopos theory determines the translation methods and strategies. If possible, translation strategies and methods are to be summarized.

\subsubsection{The Principle of Purpose}

\section{Example 1}

Shen Tao: You le qian xue hui bai jia zi le (有了钱学会摆架子了).

Getting rich has gone to your head.

Here Zhang Jinsheng becomes rich and requires Shen Tao to see himself off. His real intention is to create opportunities to be with Shen Tao. Shen Tao just makes jokes that Zhang Jinsheng is showing off. And here "bai jia zi" is translated into "Gotoone's head artfully". "Gotoone's head" means becoming dizzy with success, being ego and self-conceited. This phrase describes the mental state and behavior of Zhang Jinsheng, he is just showing off. Here to make audience understand the meaning of this sentence, the translation obeys Skopos rule and coherence rule. And domestication is used here to achieve this aim. And the use of domestication here can not only make audience easily know the mental state and behavior of Zhang Jinsheng but express the best effects.

Example 2

Zhang Jinsheng: Ni neng bu neng xian gei lao zi ba zhong wen xue hao (你能 不能先给老子把中文学好)?

Can't you learn your old man's Chinese?

Here Zhang Daole wants to quit college and asks for Zhang Jinsheng's permission in English. Jinsheng is rather angry to question Daole's ability and requires Daole to learn Chinese well firstly. "lao zi" in Chinese refers to the relationship between a father and a son and the son has no other choice but do things according to his father's willingness. In other words, father is the authority and son must conform to his father. And "Old man" is an informal term which refers to a person's husband or father. Here "old man" adheres to the fidelity rule superficially for the meaning of "laozi" is literally similar to "old man". However foreign audience may not understand what "old man's Chinese" means. As a result, it disobeys coherence rule. But to achieve the Skopos of expressing Jinsheng's mood, "old man's Chinese" is used as translation.

Example 3

Shen Tao: Li liang dong shi bu dong shi (你俩懂事不懂事)?

Do you two have no sense at all?

Here "dong shi" is full of cultural flavor. In Chinese, "bu dong shi" means that 
a person is not reasonable and fair, and does not obey the etiquette. And it can be used in various situations with various meanings. In this context, Shen Tao is right in the pain of losing her father. When she heard that her own son was to be sent to abroad, she became angry. And here "bu dong shi" refers to that Dollar's step mother didn't care about her mood of melancholy. "Have no sense" is basically equal to "bu dong shi". However, "have no sense" doesn't not indicate why Shen Tao was angry. Thus the target audience can basically understand the sentence's meaning with confusion. So example 3 follows coherence rule but disobey fidelity rule. And translation does not express the original meaning best.

It can be seen that Skopos rule is put in the first place. And sometimes coherence rule and fidelity rule are violated to different extents. Domestication is generally used to make dialogue understandable and acceptable in given context among target audience.

\subsubsection{The Purpose of Coherence}

\section{Example 1}

Shen Tao: Yi kan di li jiu mei xue hao (一看地理就没学好).

Zhong jian ge zhe tai ping yang ne (中间隔着太平洋呢).

You have to cross the Pacific to get there.

Here Shen Tao teases Zhang Jinsheng about his ignorance. And the main purpose of Shen Tao's words is to indicate that Pacific should be crossed by ship rather than car. Zhang Jinsheng cannot cross the sea by car. And "yi kan di li jiu mei xue hao" aims to make fun of Zhang Jinsheng rather than really indicate that Zhang Jinsheng's geography is bad. Thus if two sentences are translated, there are not enough room for them and it may result in redundancy. However, the translation "You have to cross the Pacific to get there" adheres to the principle of simplicity and clear meanings of sentences. It can be seen that coherence rule is followed while fidelity rule is disobeyed. However, the translation expresses the meaning clearly and accurately. Here reduction and omission are used for a much more understandable version. And at the same time it avoids redundancy artfully.

Example 2

Xiong qian dai zhe yi duo hua (胸前戴着一朵花).

Zou dao na li na li fa (走到哪里哪里发).

With such a fragrant bride, your future's bright.

Here it is a speech delivered by the host in the wedding of Oliver and Wang Ting. It is to express best wishes to this couple. Firstly, rhyme makes translation sound catchy and artful. There is end rhyme between "hua" and "fa" and between "bride" and "bright". All of them symbolize positive, beautiful and promising meaning. Secondly, "xiong qian dai zhe yi duo hua" means that the groom really has flowers on his chest literally. It also indicates that the bride is in the groom's heart. It is rather ingenious but does not mention "xiong qian" which will not show foreign audience Chinese wedding customs. Thirdly, "zou dao na li" is translated into "future" which is abstract, laconic and basically identical. 
"fa" originally refers to become thriving through a great deal. And "bright" means "giving reason to believe that good things will happen or likely to be successful". It can be found that the meaning of "bright" is more extensive than that of "fa". Therefore the translation is not thoroughly equivalent to what the host wants to express. Here it obeys coherence rule but violates fidelity rule to some extent so as to achieve the purpose of acceptability. And reduction is used for simplicity and understandability but local flavor is lost to some extent.

Example 3

Shen Tao: Ma mi? shen ren jiao ni zhe me jiao de (妈咪? 甚人教你这么叫的)

Mummy? Who taught you that?

Shuang kuai dian, jiao “ma” (爽快点, 叫 “妈” )

Be grown-up! Say "Ma".

When Shen Tao's father died, Shen Tao picks up his son from the airport to attend the funeral. Shen Tao asks Daole in shanxi dialect. But Daole timidly said "Mummy". The distance brought about by English and Shanxi dialect makes Shen Tao lose her temper. Here "shuang kuai dian" means frank or straightforward. And "grown-up" means mentally and physically an adult. The tone is relatively placid which can not indicate that Shen Tao is very angry and grieved. It obeys the coherence rule but violates fidelity rule. Moreover the color of Shanxi dialect is lost.

It can be concluded that to achieve the aim of movies, coherence rule is to be firstly followed and fidelity rule is to be secondly observed. Under this circumstance, reduction and omission are used in translation. In the meantime, local flavor is lost to some extent.

In this part, the Skopos of Mountains May Depart has been generally and specifically presented and discussed. Then examples have been selected and analyzed. To achieve basic aim, Skopos rule and coherence rule must be followed but fidelity rule may be violated to different extents. And basic methods are domestication, reduction and omission.

\section{Conclusion}

This paper has discussed Mountains May Depart's subtitle translation from the perspective of Skopos theory. Two research questions have been solved. Firstly Skopos rule runs through translation. And Skopos rule, coherence rule and fidelity rule are integrated together. Sometimes, the translation has to follow one of them and violates another. Secondly subtitle translation is supposed to be firstly understandable and acceptable to audience. So domestication or reduction to some extent is the basic method in subtitle translation, especially in the movies loaded with dialects. Next some suggestions are provided. First, to achieve the basic purpose of movies that is understandable, Skopos rule and coherence rule must be followed while fidelity rule may be obeyed or disobeyed to some extent. And the degree of fidelity is not easy to grasp. The use of domestication or reduction can generally achieve the basic aim. Second, the translation loaded 
with dialects is supposed to adhere to fidelity on the basis of coherence rule. Thus the translation retains the flavor of source culture and keeps a mystery in front of audience to some extent. At the same time local color of source text is lost to some extent. However this paper fails to delve to what extent fidelity rule would be obeyed or violated which needs to be further discussed.

\section{Conflicts of Interest}

The author declares no conflicts of interest regarding the publication of this paper.

\section{References}

[1] Dollerup, C. (1974) On Subtitles in Television Programs. Babel, 20, 197-202. https://doi.org/10.1075/babel.20.4.05dol

[2] Titford. C. (1982) Subtitling: Constrained Translation. Lebenda Sprachen, 27, 113.

[3] 麻争旗. 论影视翻译的基本原则 [J]. 现代传播一一北京广播学院学报, 1997(5): 81-84.

[4] 张春柏. 影视翻译初探 [J]. 中国翻译, 1998(2): 51-53.

[5] 钱绍昌. 影视翻译一一翻译园地中愈来愈重要的领域[J]. 中国翻译, 2000(1): 61-65.

[6] 李运兴. 字幕翻译的策略[J]. 中国翻译, 2001(4): 38-40.

[7] 赵春梅. 论译制片翻译中的四对主要矛盾[J]. 中国翻译, 2002(4): 51-53.

[8] 伍雪菲. 从接受美学角度看影视字幕翻译 [J]. 语言与文化研究 (第十一辑), 2013(1): 166-168

[9] 谭杨. 目的论视角下电视节目字幕翻译策略研究 [D]: [硕士学位论文]. 成都: 西 华大学, 2020 .

[10] Katharina, R. and Vermeer, H. (1984) Grundlegung Einer Allgemeinen Translations theorie. Niemeyer, Tubinge

[11] Christine, N. (2001) Translating as a Purposeful Activity: Functionalist Approaches Explained. Shanghai Foreign Language Education Press, Shanghai.

[12] Mark, S. and Moira, C. (2004) Dictionary of Translation Studies. Shanghai Foreign Language Education Press, Shanghai.

[13] 王甜. 贾樟柯电影艺术风格的坚守与转变[D]: [硕士学位论文]. 扬州: 扬州大学, 2017 